\title{
A sizing tool for the preliminary design of an unmanned aerial vehicle for student projects
}

\author{
Ali Dinc*, Yousef Gharbia, Abdullah Bushehri, Fawaz Al-Sarraf, Ali Al-Ali, \\ Abdulrahman M A Alsaidi, Abdulrahman Al Ruwayeh \\ *corresponding author: Ali.Dinc@aum.edu.kw \\ College of Engineering and Technology, American University of the Middle East, Kuwait
}

\begin{abstract}
This study investigates a sizing tool for the preliminary design of an Unmanned Aerial Vehicle (UAV). The UAV is designed with the aim to join and compete in the SAE Aero Design Student Competition. The sizing tool was developed in an excel spreadsheet to calculate the general dimensions of the UAV. Different designs were generated and calculated using a spreadsheet which was created to save time and effort in doing the calculations by hand. This sizing tool was used by different groups of students following the rules and regulations given by the SAE Competition rules 2018 document. The micro class aircraft must fit in a rectangular box with specific dimension in a disassembled condition. Moreover, the microclass criteria competition is scored based on which aircraft has the highest payload fraction while simultaneously the lowest empty weight possible. In this scope, multiple alternative designs for the micro aircraft were created using the dimensions obtained from sizing spreadsheet/tool. The sizing tool helped the students to explore design space with selected input and output parameters, much faster and more reliable than individual hand calculations.
\end{abstract}

Published by IJRP.ORG. Selection and/or peer-review under responsibility of International Journal of Research Publications (IJRP.ORG)

Keywords: Aircraft design; aircraft sizing; sizing tool; micro aircraft; student competition

\section{Introduction}

In the early design stages, high number of input and output parameters make the design process problematic and relatively slow to explore the whole design space. Therefore, fast design tools are needed to make many initial trials for the design concepts to be able to converge a design solution into a desired area. Preliminary sizing tool is one of the tools needed for design studies. It helps to define the general dimensions of a design, a product depending on the requirements. In this study, a sizing tool for the preliminary design of an Unmanned Aerial Vehicle (UAV) was developed. The UAV is designed with the aim to join and compete in the SAE Aero Design Student Competition. The Society of Automotive Engineers' (SAE) Aero Design competition is a competition held every year to prepare engineering students for real life engineering challenges [1]. The competition is divided into three different classes: regular, advanced, and micro class. In this research paper "Micro" class has been selected. A design and development process were needed for an operational aircraft 
with the aircraft having the highest payload with the lowest empty weight. The final score is the addition of the sub-scores which are the technical report, presentation, flight score and penalties. The objective of this project is to design and manufacture a working prototype of a UAV that can fit into a prescribed rectangular box. The UAV design process is a typical engineering design process. The aircraft design depends on several factors like competition requirements, safety protocols, and physical restrictions and in this case pandemic restrictions and more.

\section{Material and methods}

Preliminary Design of an aircraft starts with its initial sizing, so the basic literature survey was performed to find a baseline to start from when designing an aircraft. So, after literature survey was performed to get a glimpse of the competition and gaining the knowledge required to start generating designs, a spreadsheet was developed to speed up the process of calculating and preliminary designing. The spreadsheet was formulated to do the calculations automatically, in order to save time and effort and to help future innovators generate their preliminary designs for their aircraft if needed. A simplified algorithm and equations for aircraft size and weight calculations was presented in a previous work [2]. This methodology was derived from many references in literature [3-12]. Clearly, the design process is a trial-and-error process to get the best design per the requirements such as highest flight score, the highest payload and the lowest possible empty weight while still making sure that the aircraft still fits inside the given box physically. However, at the start of the design process there are a few variables that need to be assumed from literature survey, then they can be changed if needed to improve and reach the final design by many iterations. Those assumptions can be made using competitor study analysis or benchmarking study [13-15]. The initial values for the input parameters are assumed based on the literature survey as follows.

- $\quad$ Payload (PVC) length: assumed as $0.80 \mathrm{~m}$

- Payload Fraction $\left(F_{p l}\right)$ : assumed as 0.78

- Wing Loading (WL): assumed as $6.5 \mathrm{~kg} / \mathrm{m} 2$

- Aspect ratio of wing (AR): assumed as 6

- Aspect ratio of horizontal tail: assumed as 2.5

- Aspect ratio of horizontal tail: as 1.5

- Area ratio of horizontal tail to wing: assumed as 0.16

- Area ratio of vertical tail to wing: assumed as 0.07

Payload was defined as White Polyvinyl Chloride (PVC) pipe in accordance with ASTM D1785 [1]. PVC pipe outer diameter is 2.375 inches and nominal inner diameter is 2.000 inches. Total length of PVC pipes needs to be assumed as an initial value for the design to be carried attached to aircraft. This determines the weight of the total payload (PVC) to be carried, because the unit weight of PVC pipe is given as $0.680 \mathrm{lb} / \mathrm{ft}(1.012 \mathrm{~kg} / \mathrm{m})$.

Weight of $\mathrm{PVC}=1.012 \times 0.8=0.81 \mathrm{~kg}$

$$
W_{p l}=0.81 \mathrm{~kg}
$$

The total weight of aircraft $\left(W_{o}\right)$ and empty weight $\left(W_{e}\right)$ can be found as follows:

$$
\begin{aligned}
& W_{o}=\frac{W_{p l}}{F_{p l}}=\frac{0.81}{0.78}=1.038 \mathrm{~kg} \\
& W_{e}=W_{o}-W_{p l}=0.228 \mathrm{~kg}
\end{aligned}
$$

The wing loading (WL): 


$$
\mathrm{WL}=\frac{W_{o}}{S}=\frac{\text { total weight of aircraft }}{\text { wing area }}
$$

Therefore, the wing area $(\mathrm{S})$ :

$$
\mathrm{S}=\frac{W_{0}}{W L}=\frac{1.038}{6.5}=0.16 \mathrm{~m}^{2}
$$

Wing length (b)

Wing width or chord length (c)

$$
\mathrm{b}=\sqrt{A R * S}=\sqrt{6 * 0,16}=0.979 \mathrm{~m}
$$

Tail calculation:

$$
\mathrm{c}=\frac{S}{b}=0.163 \mathrm{~m}
$$

Horizontal tail: Assuming horizontal tail area is $16 \%$ of main wing area:

Assuming AR for horizontal tail=2.5

$$
\mathrm{S}_{\mathrm{HT}}=S * 0,16=0.16 * 0.16=0.026 \mathrm{~m}^{2}
$$

$$
\begin{aligned}
& \mathrm{b}_{\mathrm{HT}}=\sqrt{A R_{H T} * S_{H T}}=\sqrt{2.5 * 0.026}=0.253 \mathrm{~m} \\
& \mathrm{c}_{\mathrm{HT}}=\frac{S_{H T}}{b_{H T}}=0.101 \mathrm{~m}
\end{aligned}
$$

\begin{tabular}{|c|c|c|c|c|}
\hline \multicolumn{5}{|c|}{ Parametric UAV Sizing Tool } \\
\hline \multirow{6}{*}{$\begin{array}{l}\stackrel{\infty}{5} \\
\stackrel{0}{\underline{2}}\end{array}$} & \multirow{4}{*}{$\begin{array}{l}\text { Initial Assumptions based on } \\
\text { literature survey }\end{array}$} & WL (wing loading:Wo/S) (kg/m2) & AR (aspect ratio of wing) & Fpl (payload fraction: Wpl/Wo) \\
\hline & & 6.5 & 6 & 0.78 \\
\hline & & AR (aspect ratio Vertical Tail) & AR (aspect ratio Horizontal Tail) & Area ratio (Horz.Tail/Wing) \\
\hline & & 1.5 & 2.5 & 0.16 \\
\hline & \multirow{2}{*}{ Payload Selection/Design Choice } & Payload: unit weight of PVC $(\mathrm{kg} / \mathrm{m})$ & total Length of PVC's (m) & Area ratio (Vert.Tail/Wing) \\
\hline & & 1.012 & 0.8 & 0.07 \\
\hline \multirow{11}{*}{$\begin{array}{l}\infty \\
5 \\
\frac{5}{5} \\
0\end{array}$} & \multirow{2}{*}{ Payload Weight } & Wpl (weight of payload PVC) kg & & \\
\hline & & 0.810 & & \\
\hline & \multirow{2}{*}{ Weight of aircraft } & Wo (total aircraft weight $\mathrm{kg}$ )=Wpl/Fpl & Wempty (Wo-Wpl) kg & \\
\hline & & 1.038 & 0.228 & \\
\hline & \multirow{2}{*}{ Wing } & $\mathrm{S}$ (wing area $\mathrm{m} 2)=\mathrm{Wo} / \mathrm{WL}$ & $B$ (wingspan) (m) & $C$ (wing chord) (m) \\
\hline & & 0.160 & 0.979 & 0.163 \\
\hline & \multirow{2}{*}{ Horizontal Tail } & $\mathrm{S}$ (area horizontal tail) (m2) & $B($ span) $(m)$ & $C$ (chord) $(\mathrm{m})$ \\
\hline & & 0.026 & 0.253 & 0.101 \\
\hline & \multirow{2}{*}{ Vertical Tail } & $\mathrm{S}$ (area Vertical Tail) (m2) & B (span) (m) & $\mathrm{C}$ (chord) (m) \\
\hline & & 0.011 & 0.129 & 0.086 \\
\hline & Flight Score & $\begin{array}{c}\frac{\text { Flight Score }\left(\mathrm{Wpl} /(\mathrm{Wempty})^{\wedge} 0.5\right)}{2.515} \\
\end{array}$ & & \\
\hline
\end{tabular}

Vertical tail: Assuming vertical tail area is $7 \%$ of main wing area:

Assuming AR for vertical tail $=1.5$

$$
\mathrm{S}_{\mathrm{VT}}=S * 0.07=0.16 * 0.07=0.011 \mathrm{~m}^{2}
$$

$$
\begin{aligned}
& \mathrm{b}_{\mathrm{VT}}=\sqrt{A R_{V T} * S_{V T}}=\sqrt{1.5 * 0.011}=0.129 \mathrm{~m} \\
& \mathrm{c}_{\mathrm{VT}}=\frac{S_{V T}}{b_{V T}}=0.086 \mathrm{~m}
\end{aligned}
$$

$\therefore$ Flight Score is (weights must be in pounds in the formula):

$$
\text { Score }=W_{P L}\left(\frac{1}{W_{e}}\right)^{0.5}=0.81 * 2.204\left(\frac{1}{0.228 * 2.204}\right)^{0.5}=2.515
$$

Fig. 1. Preliminary sizing tool spreadsheet for UAV 
The above calculations are also done with "Fast Sizing Tool" which was prepared in excel. The general view of the sizing tool or spreadsheet used for the preliminary design is given in Figure 1.

Another rule in the SAE aero competition was to fit the parts of the disassembled aircraft in a box with given dimensions. The developed tool calculated the dimensions of the main parts so that it helped to estimate for the fit in the box. After some trials with the tool, students generated a design to give a good flight score while being not too big to fit into the box. After that students continued detail design process.

\section{Conclusion}

The early phases of design make the design process challenging and relatively time consuming to explore the whole design space by a large number of input and output factors. Therefore, fast design tools are needed to conduct numerous trials for concepts, so that a design solution may be converged to a desired target. Within this study, a sizing tool was developed and used by students for design studies in the preliminary sizing. Tool helps to define the general dimensions of a design, a product depending on the requirements. Additionally, the tool calculated the predicted "flight score" based on the payload and empty weight of the airplane which is one of the most important targets of the competition. In other words, this tool helped students to see the effects of payload weight, payload fraction, wing loading, aspect ratio etc. on the predicted "flight score" in the preliminary design. Another restriction in the SAE aero contest was that the dismantled airplane parts must fit in a box with a constrained size. The created tool in this study, estimated the size of the main components of airplane in order to check the fit into the box. The students were able to a reach a design configuration after some trials with the excel tool to get a good flying score while being at the acceptable size to fit into the box.

\section{Acknowledgment}

Authors would like to thank to American University of the Middle East, Kuwait for the support on the research of this study.

\section{References}

[1] SAE. SAE Collegiate Design Series: Aero Design: About Aero Design. Student Central. Web. 2018.

[2] Dinc A, Gharbia Y, Al Shammari M, Al Rasheedi A, Al Qallaf S, Al Ibrahim M, \& Al Obaid S. (2020). Preliminary design of a radio-controlled micro aircraft for student competition. Global Journal of Engineering and Technology Advances, 4(3), 64-69. https://doi.org/10.30574/gjeta.2020.4.3.0076.

[3] Raymer DP. Aircraft Design: A Conceptual Approach 4th Edition. Virginia: AIAA. 2006.

[4] Dinc A. Sizing of a Turboprop Unmanned Air Vehicle and its Propulsion System. Journal of Thermal Science and Technology. 2015; 35(2): 53-62.

[5] Dinc A. Preliminary Sizing and Performance Calculations of Unmanned Air Vehicles. In T. Shmelova, Y. Sikirda, N. Rizun, D. Kucherov, \& K. Dergachov (Eds.), Automated Systems in the Aviation and Aerospace Industries. Hershey, PA: IGI Global. 2019; 242-272. doi:10.4018/978-15225-7709-6.ch009

[6] Dinc A. Sizing of a Turboprop Engine Powered High Altitude Unmanned Aerial Vehicle and It`s Propulsion System for an Assumed Mission Profile in Turkey. International Journal of Aviation Science and Technology, vm01 (is01). 2020; 5-8. doi:10.23890/IJAST.vm01is01.0101 
[7] Dinc A., \& Elbadawy I. Global warming potential optimization of a turbofan powered unmanned aerial vehicle during surveillance mission. Transportation Research Part D: Transport and Environment, 85, 102472. 2020; doi:10.1016/j.trd.2020.102472

[8] Dinc A. NOx emissions of turbofan powered unmanned aerial vehicle for complete flight cycle. Chinese Journal of Aeronautics, 33(6), 1683-1691. 2020; doi:10.1016/j.cja.2019.12.029

[9] Dinc A., Gharbia, Y. Improving Flight Endurance of a UAV by Employing Porous Wing Tip. American Journal of Engineering Research, vol. 7, no. 11, pp.177-181.2020

[10] Dinc A. Optimization of turboprop ESFC and NOx emissions for UAV sizing. Aircraft Engineering and Aerospace Technology, 89(3). 2017; doi: 10.1108/AEAT-12-2015-0248

[11] Dinc, A., Taher, R., Moayyedian, M., Bushehri, A., Alruwayeh, A., Alali, A., \& Alsarraf, F. (2020). A Performance Review of a High Altitude Long Endurance Drone. International Journal of Progressive Sciences and Technologies, 24(1), 32-39

[12] Dinc A. Optimization of a Turboprop UAV for Maximum Loiter and Specific Power Using Genetic Algorithm. International Journal of Turbo \& Jet-Engines, 33(3), pp. 265-273. 2015; doi:10.1515/tjj2015-0030

[13] Andrews S, Grossman PB, Hendricks SM, Hong G, McKenzie C, Morette K. Design of a Micro-Class Aircraft for the SAE AeroEast Heavy Lift Competition. Worcester Polytechnic Institute. 2012.

[14] Capozzi R, Chretien E, Clanton S, Daci E, Jones T, Libby A, Peccerillo S, Rice B, Russell J, Sajjadi K, Smith C, Tokatli N. Remote Control Aircraft for the SAE Aero Design West Competition. Worcester Polytechnic Institute. 2018.

[15] Waller B, Chandpen D, Travaglini J, Maberry M, Cushman T, Veilleux Z. Design, Construction and Testing Of A Remote Operation Heavy-Lift Model Aircraft. University of Maine. 2013. 